\title{
Can the CAP cope with the enlarged European Union?
}

\author{
Jukka Kola \\ Taloustieteen laitos, PL 27,00014 Helsingin yliopisto,jukka.kola@,helsinki.fi
}

\section{Introduction: Diversity - an advantage or a problem?}

Diversity is often regarded as the richness and advantage of the EU, at least in many official speeches made by the Commission representatives, all the way up to Commissioner Franz Fischler. But at the same time we should ask whether it is possible, or sensible, to have a common agricultural policy in the EU especially as it will become even more diverse after enlargement, i.e. as the EU-15 will become the EU-25.

The CAP was made for the six founding Member States of the EU: now there are 15 Member States, and in 2004 there will be 25 Member States. How has the CAP developed and responded to the changes in the EU during 40 years? Is it still, or has it ever been, common and fair enough for all Member States, including such northern countries as Finland, or southern country as Portugal? What about the Eastern Enlargement and the so-called commonness of agricultural policy?

\section{Objective and methodology}

The objective here is to explore how the common agricultural policy (CAP) of the EU has developed in the past decades and how it will develop in relation to the EU enlargement to the Central and Eastern European countries (CEECs). The methodology is based on the approach of new political economy. The key characteristics of the agricultural sectors and societies in general, in addition to national policy preferences, are employed as explanatory factors. A special attention is paid to multifunctionality and its role in the reformed CAP, especially in terms of the future EU-25.

\section{Political economy and policy preferences of Member States}

There seems to be quite broad approval and commonness in the objectives of the CAP, though they were made 40 years ago for the six original Member States only. The real problem is the uneven, nontargeted, unconditional and inefficient subsidising of EU farmers: the notorious rule is that 20 per cent of EU farmers receive 80 per cent of CAP support. These farmers often have the largest farms located in the best arable areas with the highest yields in the EU. It is exactly they who need not be subsidised most heavily from the common budget.

This distorted situation did not change in the reforms of the CAP in 1992 or in the Agenda 2000 for the period of 2000-2006. Farmers in the most-favoured areas have received more than double the amount per hectare in CAP arable area payments compared to farmers in the less favoured areas of Finland and Portugal. This difference has existed for almost ten years. There is no reason to continue it. If support per hectare were the same throughout the EU we would have a much more common and fair policy. The EU could make much needed savings with a common rate set clearly below the current top levels.

The EU Commission's CAP Mid-Term Review, originally introduced in the summer 2002, made an ambitious attempt to create a real reform, but it was blocked mainly by France. Finally, the CAP reform of June 2003 mainly maintained the prevailing subsidy biases in spite of some innovative aspects in terms of decoupling and modulation. Consequently, the subsidy biases remain in tact.

The EU Commission's own statistics show (Figure 1) that because the CAP rewards high yields, big farms, and big exporters, farms in Denmark and the UK have received on average more than $€ 18,000$ per farm from the Guarantee section. In contrast farms in the less-favoured agricultural areas of the Southern Member States receive in the range $€ 1,600-4,100$ per farm, the EU average being about $€ 5,700$. The most recent member states of the 1995 enlargement with arctic and alpine conditions, Finland and Austria, do not do very well either. These differences have not changed to any meaningful extent as we have entered the new millennium. Nor does it change in the CAP reform of June 2003. 
Moreover, the less-favoured areas (LFA) support does not change this picture very much at all as this aid is also allocated to all Member States, though in different degrees and extent. The traditional forms of support in the EAGGF Guarantee section account for 90 per cent of the EU's total agricultural budget. Accordingly, it is clear that the CAP measures do not mitigate regional differences to a sufficient extent, i.e. the CAP is not common enough.

The old CAP is just not capable of meeting the needs of the new member states. Moreover, as there are no support ceilings or thresholds in the CAP, many big farms receive hundreds of thousands of euros of taxpayers' money for no rational reason.

European citizens would benefit if support ceilings per farm were set. The United States established such ceilings in the 1996 FAIR Act and continues to have them also in the new farm bill (Farm Security and Rural Investment FSRI Act 2002), but the EU was unable to do the same in Agenda 2000, and also in the 2003 reform, for reasons linked to the political economy of Member States. The absolute ceiling could be set at, say, $€ 100,000$ or even less when we consider the current EU average or the basic US limits.

It seems clear, too, that the multifunctionality goal of agriculture could be secured with lower subsidy payments per farm and per hectare, especially in the most-favoured agricultural regions.

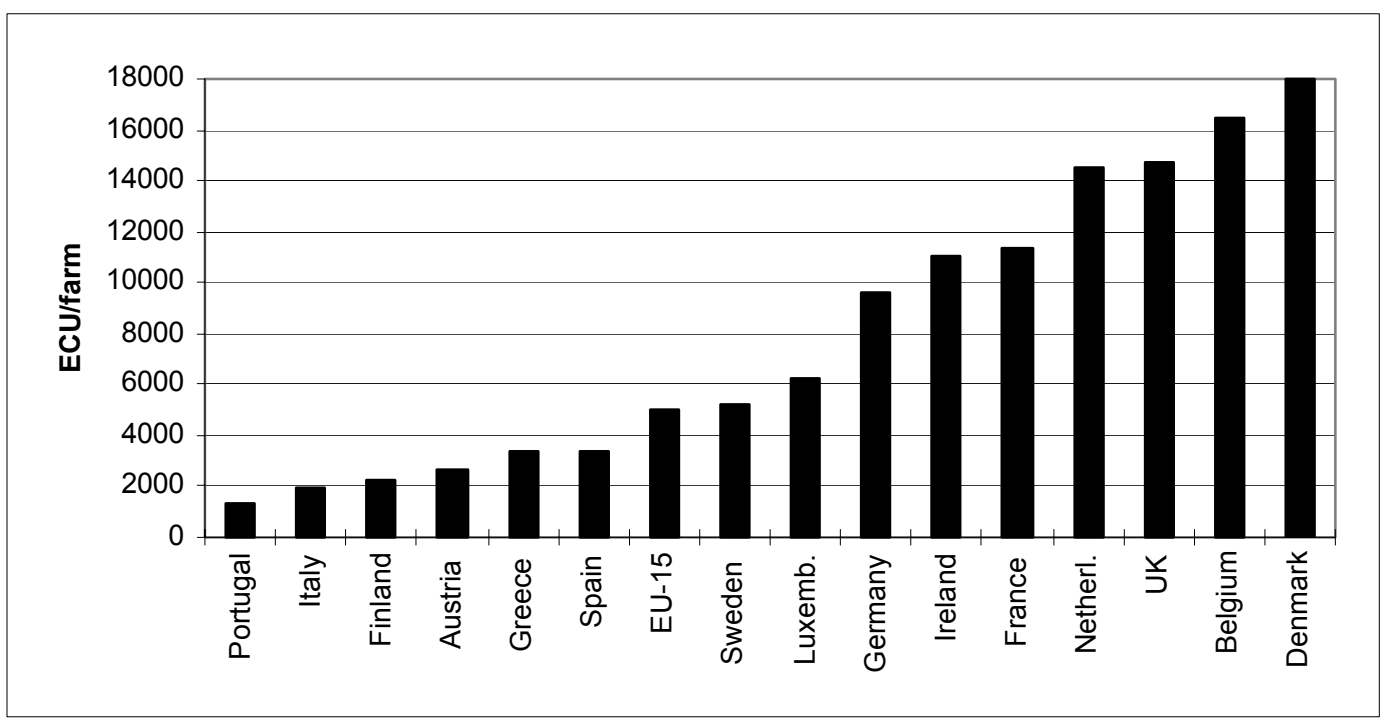

Figure 1. CAP expenditure in the Member States, ecu per farm annually in the period of 1995-97 (Source: EU Council (1998). Agenda 2000: Distribution of EAGGF Guarantee Expenditure. European Union, The Council. SN 2239/98, 14 September 1998. Brussels).

\section{Special analysis: Multifunctionality - good goal, bad means; and how to accommodate the CEECs?}

Multifunctionality of agriculture is today a key concept in the EU. Yet, the allocation and forms of the current CAP spending do not advance multifunctionality very much at all. By pursuing the CAP with the current instruments the Commission simply undermines its own goal, a goal which it is strongly advocating in the WTO. This new goal requires a revised allocation and new types of support to enhance multifunctionality throughout the EU. Although, arguably, this is not a rational goal in purely economic or budgetary terms, it is, nevertheless, a widely accepted common decision in the EU. EU policies should advance it, not hinder it.

The CEEC candidate Member States are now being told that they are not entitled to CAP support because their prices will rise, not fall. But might they not claim that they are indeed entitled to receive multifunctionality support, given the EU case in the WTO that its agricultural support is for the maintenance of the multifunctionality of agriculture throughout the EU? Payment of these supports would help to increase the commonness of the CAP. 
For European taxpayers it would be better, both for economic and equity reasons, if CAP and other policy supports were more clearly allocated and targeted to the most important objectives and to those most in need. The CAP must serve more clearly and efficiently the new and more consumer, environment and rural-oriented objectives of the entire EU. Paying the highest subsidy to farms with the most productive land, or to an industrialised large-scale livestock unit in the most intensive farming systems cannot be the direction desired by European citizens.

Proper and true multifunctionality support, the equalisation of support per hectare and support ceilings per farm, together, would contribute to greater policy efficiency and effectiveness.

Policy-makers in their decisions and agricultural economists in their analyses should pay more attention to cost-benefit and cost-impact analyses of the CAP, especially to that major part of expenditure that is fully financed by the common budget of the so-called common policy. What do we get from the huge expenditure of the CAP and is it what we really want as European citizens, taxpayers and consumers?

\section{Conclusions - and lessons for the CEECs ${ }^{1}$}

Which of the experiences faced by the most recent entrants to the EU, i.e. the three EFTA-countries of Austria, Finland and Sweden, are relevant for the CEECs in general, and for the Baltic States in particular? First of all, one could have expected that the swift process of negotiations were not very likely to be repeated. However, the process was after all surprisingly short, though some doubts remain that everything is not unambiguously enough agreed on. Nevertheless, in both of the cases the negotiating of the Accession Treaties was a major effort, implying a strong call on the resources and skills. This is true even for the highly developed countries of EFTA-3, but in particular for the CEECs, in which even some of the institutions and inherent personnel were non-existent due to a different systems in administration and in the (agricultural) policy planning and making as a whole. In fact, this lack of some institutional and administrative systems may prove as a hindrance to the actual implementation of the CAP, and probably even more so in the case of the Structural Funds.

In both cases, but especially for the CEECs, the EU demonstrated a considerable degree of flexibility and creativity in inventing new solutions to enable the enlargement to take place in a planned timetable. Reaching an agreement on eastern enlargement certainly demanded lot of creativity and willingness to find new solutions and mutually beneficial compromises. However, with the EFTA-3 the process of reaching a compromise was facilitated, to some degree, by allowing the new members to keep their favoured policies and pay themselves for them. This possibility was also offered for the CEECs, but its use will be relatively much more limited due to financial constraints in the new members. Further renationalisation of the CAP, and an increased emphasis on the subsidiarity principle of the CAP, were realised in the EFTA-enlargement and will be realised also in the eastern enlargement. It will inevitably be the future direction of the CAP; it will be the way how the EU and its CAP will cope with the enlarged Union.

The outcome of the EFTA-3 accession demonstrated a willingness to protect or even preserve farm income to a high degree. But it also showed an insufficient ability to deal with the difficulties of the primary processing, which will most likely be considerable in many of the CEECs. In the EFTA-3 many adjustments, in fact, took place before entering the common market, which is not the fact for the CEECs in general, although the EU has provided so-called restructuring funds to the CEECs in the early 2000s. Foreign direct investment (FDI) and international companies, especially when establishing in the CEECs, have also helped in the structural development of the farming and processing sectors in some CEECs. At the same time, they have increased competition.

With respect to the CEECs and the Baltic States, too, an improvement in competitiveness in the processing industry seems to be an important prerequisite. Partly, this process is already going on in the candidate countries with the EU, which is supporting such activities through

\footnotetext{
${ }^{1}$ This chapter is partly based, in an up-dated form, on: Kola, J., Hofreither, M. \& Rabinowicz, E. 2000. Experience of EU accession for the agricultural sector: Austria, Finland and Sweden. In: Burrell, A. \& Oskam, A. (editors): Agricultural Policy and Enlargement of the European Union: 143-162. Wageningen Pers, The Netherlands. 252 p.
} 
the pre-accession measures. Agriculture of the CEECs, in turn, is shifting in most countries from a lower price level to a higher one, which should make accession easier for the farming sector, but may contribute to production surpluses in the medium or long term. Consumers are likely to suffer from higher food prices.

In the 1980s the Southern enlargement (Greece, Portugal and Spain) was based on a long transition period of up to 10 years and the use of accession compensatory amounts (ACAs). This option was not allowed by the EU to be used in the EFTA-accession. The fact that the internal market was completed in the early 1990s made it more cumbersome, in fact impossible, to rely on the ACA option. Accordingly, it was quite clear that this option was straightforwardly excluded in the Eastern enlargement; it was unrealistic in the current conditions.

In terms of the lessons we could learn from the earlier enlargements, we need to remember and reflect on at least three facts: (1) The candidate countries are very different from the EFTA-3 and the Mediterranean countries of the two previous enlargements, (2) the candidate countries are very different from each other, and (3) the CAP is not the same as it was in the 1980s and 1990s. For example within the CEECs, in Poland about $20 \%$ of the population is still employed in agriculture, in the Czech Republic the share of agriculture is less than that of the OECD average. In Slovenia prices are close to the EU level already.

Accordingly, future priorities and actions of the new members may differ considerably. As a whole, they were not treated differently in the accession negotiations. Will this cause problems in the future, either in the new member states or in the EU as a whole? Should the CEECs have been treated differently, or more specifically in the negotiations due to their specific, different characteristics and preferences? Looking at the EFTA and CEECs Accession Treaties, it appears to be that the ambition (at least of the EU Commission) has been to find common solutions to common problems facing the applicants rather than rely too much on a specific national solutions for each of the newcomers. With regard to the resources involved in the process of negotiation, it could be asked whether the CEECs encountered difficulties in investing enough resources to watch over their (specific national) interests in the process of negotiations.

The new Member States are now being told that they are not entitled to full CAP support, only for $25 \%$ in the first year of membership and then gradually rising, because their prices will rise, not fall. But might they not claim that they are indeed entitled to receive multifunctionality support, given the EU case in the WTO that its agricultural support is for the maintenance of the multifunctionality of agriculture throughout the EU? Payment of these supports would help to increase the commonness of the CAP.

Hence, we can conclude that if the EU were as serious with the concept of multifunctional agriculture at home as it seems to be especially. in the WTO negotiations, it should change the allocation and forms of the CAP support in order to truly enhance the multifunctional characteristics of agriculture, also, and in particular, in the less-favoured agricultural areas of Europe, including also and especially the CEECs. The CAP reform of June 2003 and the Accession Treaties of the CEECs fail clearly to do this, which means that - due to both internal and external reasons - we can expect further CAP reforms much sooner than the currently proposed year of 2014 